\title{
ADSORPTIVE REMOVAL OF PHOSPHATE ONTO IRON LOADED LITCHI CHINENSIS SEED WASTE
}

\author{
Asmita Shrestha $^{1}$, Bhoj Raj Poudel ${ }^{2}$, Manoj Silwal ${ }^{1}$, Megh Raj Pokhrel ${ }^{1 *}$ \\ ${ }^{1}$ Central Department of Chemistry, Tribhuvan University, Kirtipur, Katmandu, Nepal \\ ${ }^{2}$ Department of Chemistry, Tri-Chandra Multiple Campus, Tribhuvan University, Nepal \\ Corresponding author: meghrajpokhrel2000@ymail.com
}

(Received: August 8, 2018; Revised: December 17, 2018; Accepted: December 19, 2018)

\begin{abstract}
Raw and charred Fe(III)-loaded Litchi chinensis seed waste (FeRLW and FeCLW) as bio-adsorbents was investigated to remove phosphate from aqueous solution. Various physico-chemical parameters such as equilibrium time, $\mathrm{pH}$ and adsorbent dosage were studied by batch experiment method. The maximum adsorption capacities for phosphate removal by FeRLW and FeCLW were found to be $96.5 \mathrm{mg} / \mathrm{g}$ and $100 \mathrm{mg} / \mathrm{g}$, respectively. The experimental results revealed that biomaterials of FeRLW and FeCLW can be used as effective and economically viable adsorbents for the removal of phosphate from waste water.
\end{abstract}

Keywords: Phosphate, Adsorption, Bio-adsorbent, Litchi waste, Adsorption kinetics

\section{INTRODUCTION}

Phosphorus is essential to sustain life and is required by all living cells. Due to its ability to promote the growth of plant, it is used as fertilizer. A process of eutrophication occurs when excess amount of phosphate from agricultural run-off enters into lakes and rivers and thereby, render the water sources to be incapable of supporting plant and animal life and ultimately lake dies (Batchelor \& Dennis 1987). Phosphate and nitrate discharged into the environment disturb the balance of aquatic organisms and affect the water quality, mainly through depletion of dissolved oxygen due to the decay of algae (Inoue et. al. 2018). Phosphates are important for many industries. Phosphorous is often present at low concentration in wastewater in the form of phosphate and polyphosphate (Zeng et al. 2004). Surface run-offs contribute to an extent of $65 \%$ of phosphate pollution. Industrial wastes from detergent manufacturing and fabric treatment add to about $25 \%$ and domestic and municipal sewages accounts to about $15 \%$. Hence, there is growing awareness towards the phosphate pollution in the world. Some countries have made legislation and introduced phosphate control acts, for example Switzerland banned the use of phosphate in detergent (Ravindhranath et al. 2011).

Waste or contaminated water is a big environmental problem in the world. In industrial plants; contaminants may be a result of side reactions, rendering the water stream an effluent status. These impurities are at low-level concentration but still need to be further reduced to levels acceptable by various destinations in the plant. Surface water contains phosphorus in various forms. In natural conditions the phosphorus concentration in water is balanced, i.e., accessible mass of this constituent is close to the requirements of the ecological system. It has been estimated that a person contributes to about 2-3 $\mathrm{g}$ of phosphorus in wastewater every day (Tchobanoglous \& Burto 1991). The problem of excess phosphorus content occurs when the input of phosphorus in waters is higher than it can be assimilated by a population of living organisms. Regulatory control on phosphorus disposal is evident all over the world in recent years. Strict regulatory requirements decreased the permissible level of phosphorus concentration (i.e., up to $1 \mathrm{mg} / \mathrm{L}$ ) in wastewater at the point of disposal. Hence, it is necessary to find an appropriate solution for treatment of wastewater prior to disposal.

Before discharging the wastewater into water bodies, removing phosphate is mandatory. The wastewater treatment industries currently use several methods to remove phosphorus; some are large-scale treatment facilities and some are still on a small-scale basis. Phosphorus is removed by converting the phosphorus ions in wastewater into a solid fraction which can be precipitated in the form of insoluble phosphate salts, a microbial mass in an activated sludge or a plant biomass in constructed wetlands. These approaches do not recycle phosphorus as a truly sustainable product, because it is removed with various other waste products, some of which are toxic. The precipitated phosphates are either buried at landfills after incineration of the organic matter or used as sludge fertilizer, if the treatment facility eliminates human pathogens and toxic compounds. It was reported that a special attention should be given to biological phosphorus removal and its recycling as a raw material for the phosphate industry (Bashan \& Bashan 2004).

Different methods of phosphorous removal from wastewater such as chemical precipitation, crystallization including MAP (magnesium ammonium phosphate) and 
HAP (hydroxyapatite) process, ion exchange, ultrafiltration, adsorption and biological methods have been extensively studied during last decades. Anion exchangers are also commonly used but they have several shortcomings like low selectivity in the presence of other competing anions. In general, activated alumina and chelating resins are considered as the most effective but these are too expensive for waste water treatments (Biswas et al. 2008). Removal of phosphate by means of adsorption has been studied in recent years with the use of various adsorbents. There is a growing trend of using agricultural waste or by-products (AWBs) as substrates for the development of phosphate bio-sorbents. However, due to lack of anion binding sites, natural or raw AWBs are usually inefficient in phosphate removal. Consequently modification plays an important role in improving phosphate sorption's properties of the raw AWBs. It was reported that the modification can significantly enhance phosphate removal capacity of AWBs by retaining phosphate ion on to modified AWBs mainly through ion exchange and ligand exchange mechanisms (Nguyen et al. 2014). Besides, modification of AWBs was found to increase the stability of lignocelluloses materials and hence prevent the leaching of organic matters into aqueous solution (Anirudhan et al. 2006). The modification methods of AWBs for better phosphate removal can be grouped into (i) cationization (metal loading, grafting with ammonium type chemicals), (ii) anionization (surface costing) and (iii) activation by thermal, chemical and steam.

Various bio-sorbents loading with multivalent metals have been used in phosphate removal from aqueous solution such as zirconium loaded orange waste gel (Biswas et al. 2008) and apple peels (Mallampati \& Valiyaveettil 2013), lanthanum-, cerium- or iron-loaded orange waste gel (Biswas et al. 2007), iron-loaded okara (Nguyen et al. 2013), eggshell (Mezenner \& Bensmaili 2009), coir pith (Krishnan \& Haridas 2008) and lanthanum-loaded juniper fiber ( Shin et al. 2005). In this context, present research work was aimed to prepare adsorbent of Litchi chinensis seed waste loaded with Fe(III) ion, investigate its sorption capacity, $\mathrm{pH}$ dependence, kinetic behavior, and to evaluate the adsorptive capacity of iron-loaded raw and charred Litchi chinensis waste adsorbents to remove phosphate from aqueous solution.

\section{MATERIALS AND METHODS}

\section{Preparation of adsorbent}

Litchi seed waste was collected from different locations of Palpa district, Nepal. It was cleaned with distilled water and exposed to sunlight for 10 days to completely dry. The dried litchi seed was grinded by a mechanical grinder and then it was passed through sieves of size $150 \mu \mathrm{m}$ to obtain powder with definite particle size which was named as raw litchi waste (RLW). About $400 \mathrm{~g}$ of RLW was mixed with $800 \mathrm{~mL}$ concentrated sulphuric acid in a plastic bucket and left for 24 hours. The process of the raw sample treatment with concentrated sulphuric acid is called charring process. After 24 hours, it was washed with distilled water to bring $\mathrm{pH}$ to neutral and dried at 80 ${ }^{\circ} \mathrm{C}$ for 8 hours using hot air oven. The dried sample was sieved and the powder was named as charred litchi waste (CLW).

To create the adsorption sites for phosphate, $\mathrm{Fe}(\mathrm{III})$ was then loaded on to RLW and CLW, where $5 \mathrm{~g}$ of each was mixed separately with $500 \mathrm{~mL}$ of $0.2 \mathrm{M}$ hydrated ferric chloride $\left(\mathrm{FeCl}_{3} \cdot 6 \mathrm{H}_{2} \mathrm{O}\right)$ solution, and stirred for $24 \mathrm{hrs}$ at $25{ }^{\circ} \mathrm{C}$ for the loading reaction. The mixture was then filtered and the filter cake was washed several times with distilled water to remove un-adsorbed Fe(III) ions and were dried in oven at $70{ }^{\circ} \mathrm{C}$. Thus prepared Fe(III)-loaded RLW and CLW are abbreviated as FeRLW and FeCLW, respectively.

\section{Batch adsorption studies}

Batch adsorption experiment was carried out with standard working solution of phosphate of known concentration and adsorbent of FeRLW and FeCLW. The working solution of required concentrations of phosphate was prepared by diluting $15 \mathrm{mg} / \mathrm{L}$ of phosphate solution. $\mathrm{pH}$ of the phosphate solution was adjusted using $\mathrm{HCl}$ and $\mathrm{NaOH}$ solutions in present work. Then $25 \mathrm{~mL}$ of the $\mathrm{pH}$ adjusted working solution of phosphate was taken in a 50 $\mathrm{mL}$ conical flask in which $25 \mathrm{mg}$ of FeRLW or FeCLW bio-adsorbent was added to the corresponding conical flasks. Each conical flask was shaken for definite time periods using a mechanical shaker to attain equilibrium. The equilibrated solution was filtered using ordinary filter paper and filtrate was analyzed for the residual concentration of phosphate. The phosphate concentration before and after adsorption was determined by molybdenum blue method using WPAS104 spectrophotometer after obtaining the calibration curve at maximum wavelength $\left(\lambda_{\max }\right)$ at $830 \mathrm{~nm}$ (Bashan \& Bashan 2004, Bhattarai 2012). The $\mathrm{pH}$ of the sample solution was measured using $\mathrm{pH}$ meter (LI613, ELICO-245) using glass electrode.

The batch experiments were carried out by varying the experimental conditions such as $\mathrm{pH}$, adsorbent dosage, initial phosphate ion concentration and contact time. The percentage adsorption of phosphate ions (A\%) and the amount of phosphate ions adsorbed $\left(\mathrm{q}_{\mathrm{e}}\right)$ were calculated using following equations (1) an (2), respectively:

$\mathrm{A} \%=\frac{\mathrm{Ci}-\mathrm{Ce}}{\mathrm{Ci}} \times 100$
$\mathrm{q}_{\mathrm{e}}(\mathrm{mg} / \mathrm{g})=\left[\frac{\mathrm{Ci}-\mathrm{Ce}}{\mathrm{W}}\right] \times \mathrm{V}$

Where, $\mathrm{C}_{\mathrm{i}}$ and $\mathrm{C}_{\mathrm{e}}$ are initial and equilibrium phosphate concentration $(\mathrm{mg} / \mathrm{L})$, respectively; $\mathrm{V}$ is the volume of 
feed solution in litre and $\mathrm{W}$ is the weight $(\mathrm{g})$ of dry adsorbent.

\section{RESULTS AND DISCUSSION}

\section{Effect of pH on phosphate adsorption}

The $\mathrm{pH}$ of solution is the most important parameter governing adsorption of ionic species because $\mathrm{H}^{+}$ions themselves are strong competing ions and partly $\mathrm{pH}$ influences the chemical speciation of the adsorbate and functional groups available on the adsorbent surface. The effect of $\mathrm{pH}$ on phosphate adsorption onto FeRLW and FeCLW was examined in a series of experiment by shaking $25 \mathrm{mg}$ of each adsorbent with the initial phosphate concentration of $20 \mathrm{mg} / \mathrm{L}$ to maintain the $\mathrm{pH}$ values between 1 and 6 . The $\mathrm{pH}$ effect on the sorption efficiency of phosphate on both the bio-adsorbents is shown in Fig. 1.
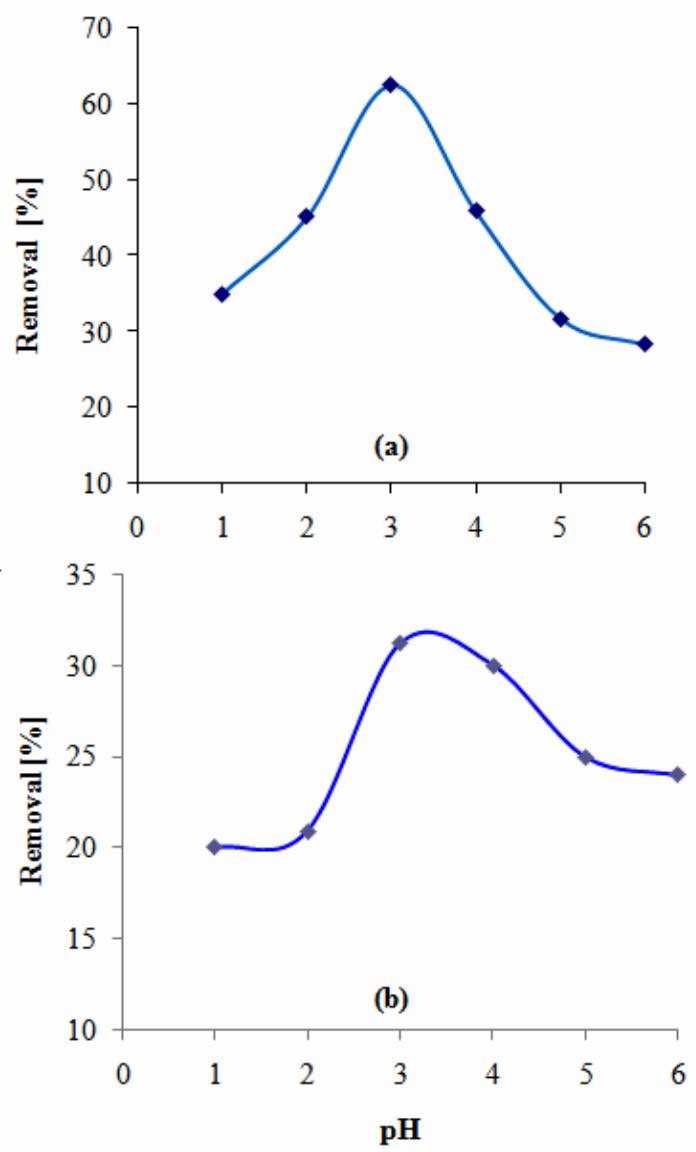

Fig. 1. Effect of pH on the adsorption of phosphate onto (a) FeCLW and (b) FeRLW

The removal of phosphate occurred in acidic $\mathrm{pH}$ and maximum adsorption was found to be achieved at $\mathrm{pH} 3$ for both FeCLW and FeRLW as shown in Figs 1(a) and 1(b), respectively. This can be explained by the fact that at $\mathrm{pH} 3$, phosphate exists as the anion $\mathrm{H}_{2} \mathrm{PO}_{4}{ }^{-}$, whereas bioadsorbent surface become positively charged; so the adsorption of anionic phosphate may be a result of electrostatic attraction between $\mathrm{H}_{2} \mathrm{PO}_{4}{ }^{-}$and the positively charged bioadsorbent surface (Bhattarai 2012, Pradhan \& Pokhrel 2013).

\section{Effect of adsorbent dose}

The effect of adsorbent dose was studied by taking various amounts (i. e., $25 \mathrm{mg}$ to $250 \mathrm{mg}$ ) of each bioadsorbent separately with $20 \mathrm{mg} / \mathrm{L}$ initial concentration of phosphate solution at optimum $\mathrm{pH} 3$. The removal of phosphate was found to be increased with increasing of the adsorbent dosages and the removal remained almost unchanged after adsorbent dose of $175 \mathrm{mg}$ for both FeCLW and FeRLW bio-adsorbents as shown in Figs 2(a) and 2(b), respectively.
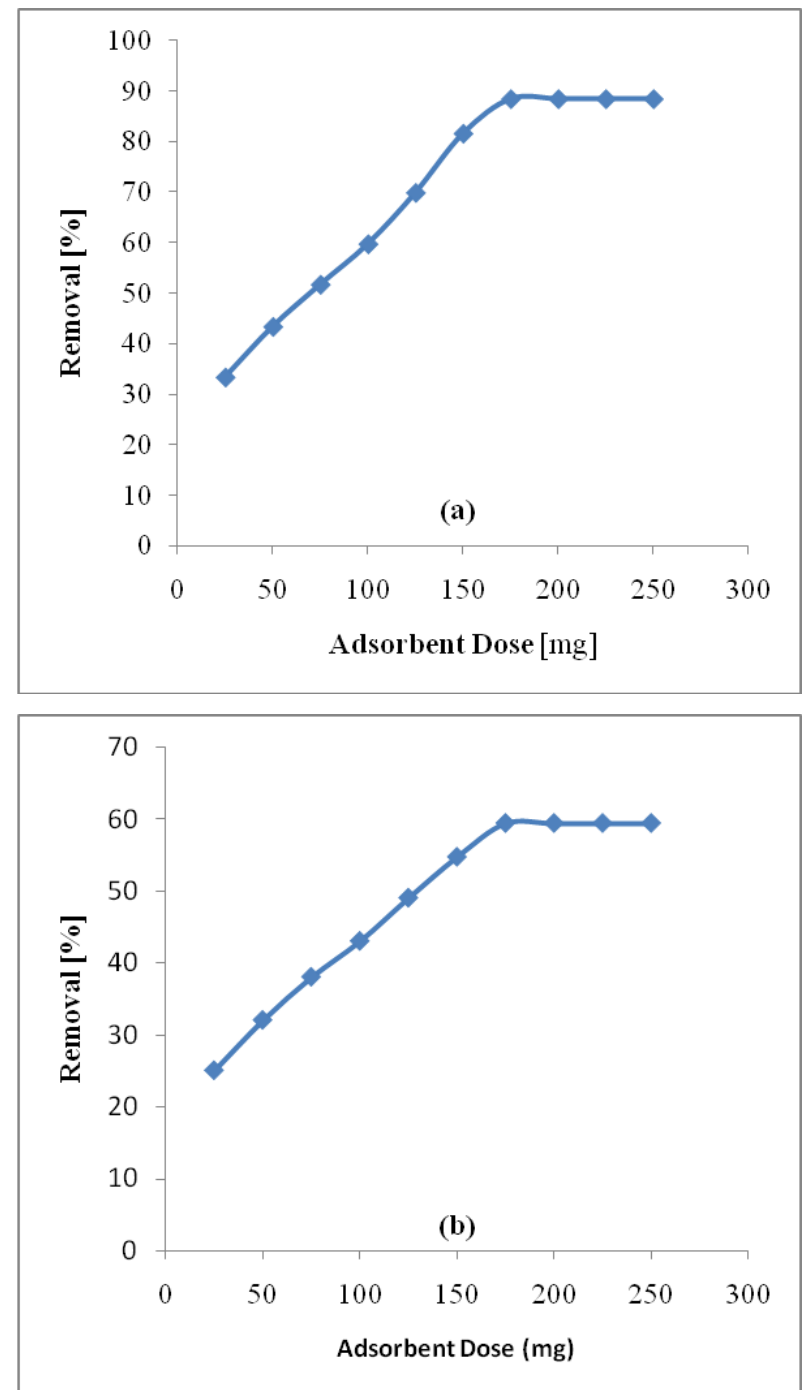

Fig. 2. Effect of adsorbent dose on the adsorption of phosphate onto (a) FeCLW and (b) FeRLW

Increase in adsorption with increasing of the adsorbent dosage attributed to the availability of large surface area and more adsorption sites on the surfaces of both bio- 
adsorbents of FeCLW and FeRLW. At low adsorbent dose, the adsorbent surface becomes saturated with phosphate and the corresponding residual phosphate ion concentrations in the solutions are large (Lu et al. 2009).

\section{Effect of contact time}

The rate of adsorption is the most important for performing the batch adsorption experiment. The experimental study measuring the effect of contact time on the batch adsorption of $1.5 \mathrm{mg} / \mathrm{L}$ phosphate with $25 \mathrm{mg}$ of each adsorbent of FeCLW and FeRLW is shown in Fig. 3. The equilibrium contact time for adsorption of phosphate onto FeCLW and FeRLW reached within the first 240 minutes for both adsorbents used in this study and beyond that saturation level is reached as shown in Figs 3(a) and 3(b), respectively.
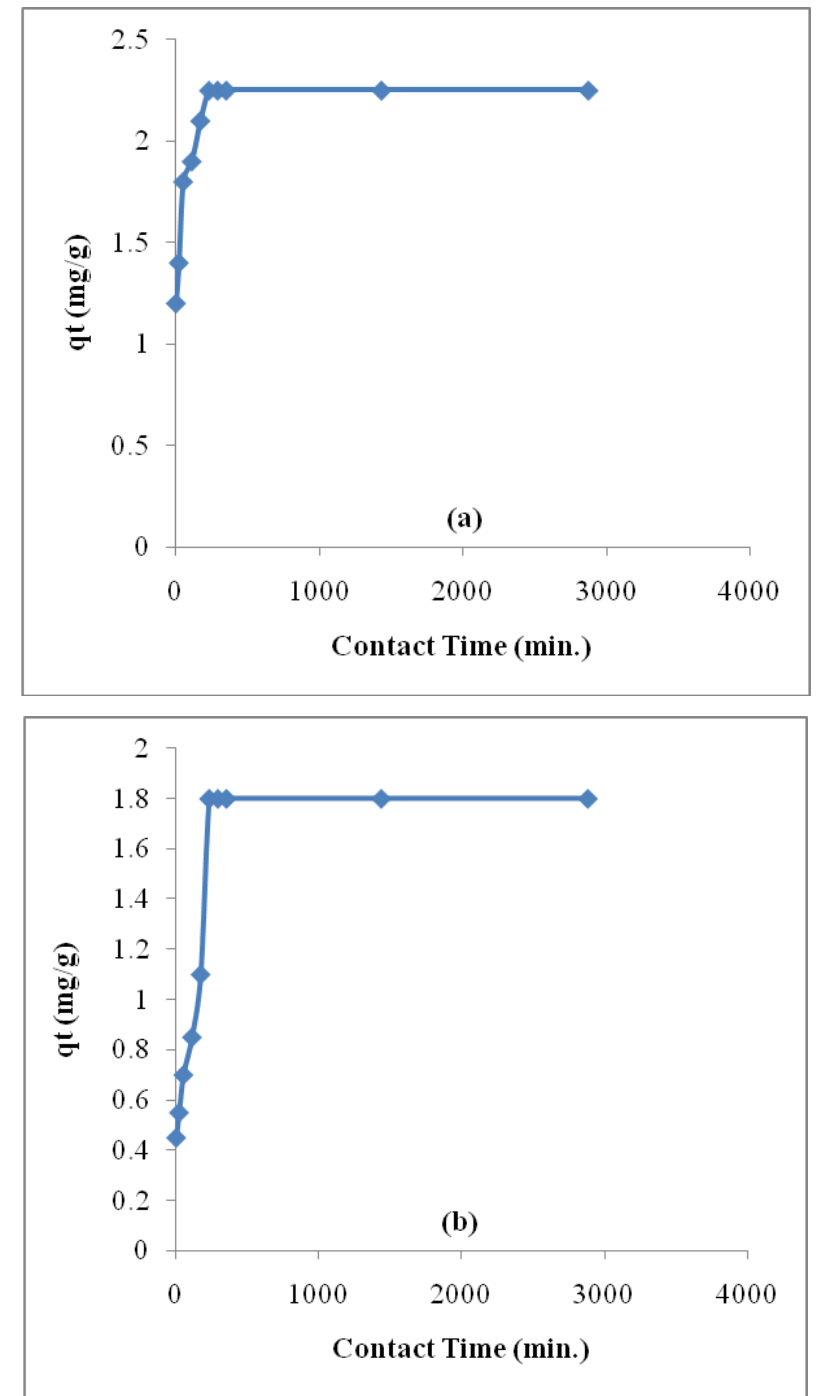

Fig. 3. Effect of contact time on the adsorption of phosphate onto (a) FeCLW and (b) FeRLW

From the data, it was found that the adsorption rate was rapid at first because of the presence of large number of adsorption sites or complexation sites so that large amount of phosphate ions attached selectively to the adsorbent sites initially. The rate slowed down gradually till it attained equilibrium at specific time for both FeCLW and FeRLW bio-adsorbents, beyond which there was no significant increase in adsorption rate due to decrease in active sorption sites in the adsorbent and after reaching the saturation point adsorption becomes constant (Bhattarai 2012).

\section{Effect of initial concentrations of phosphate}

The effect of initial concentrations of phosphate on its adsorption onto FeCLW and FeRLW was studied by varying its concentration from 100 to $500 \mathrm{mg} / \mathrm{L}$. The amount of adsorbent taken and $\mathrm{pH}$ for this study were 25 $\mathrm{mg}$ and 3, respectively. Figures 4(a) and 4(b) show that the adsorption of phosphate onto FeCLW and FeRLW increased with increasing in the initial concentration of phosphate solutions and attained equilibrium which was attributed to the availability of limited sorption sites.

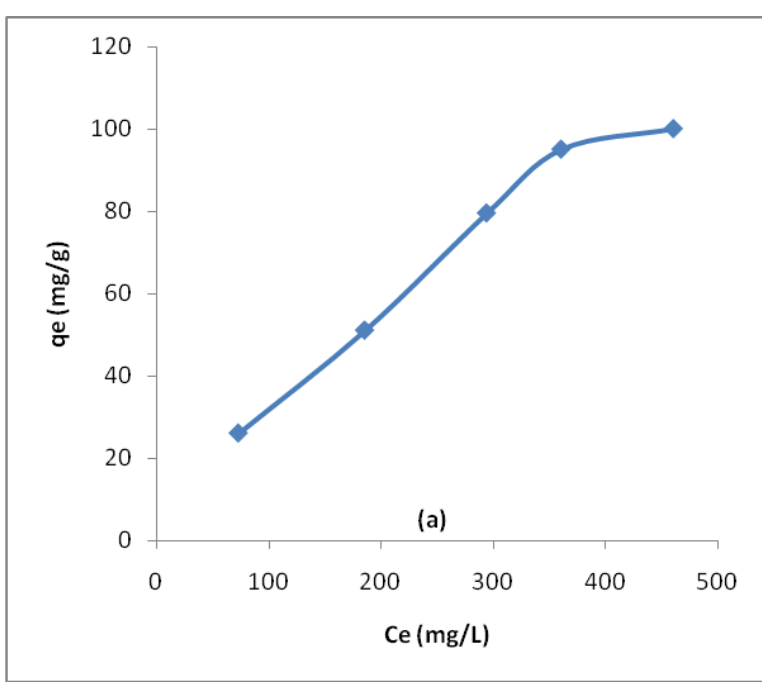

120

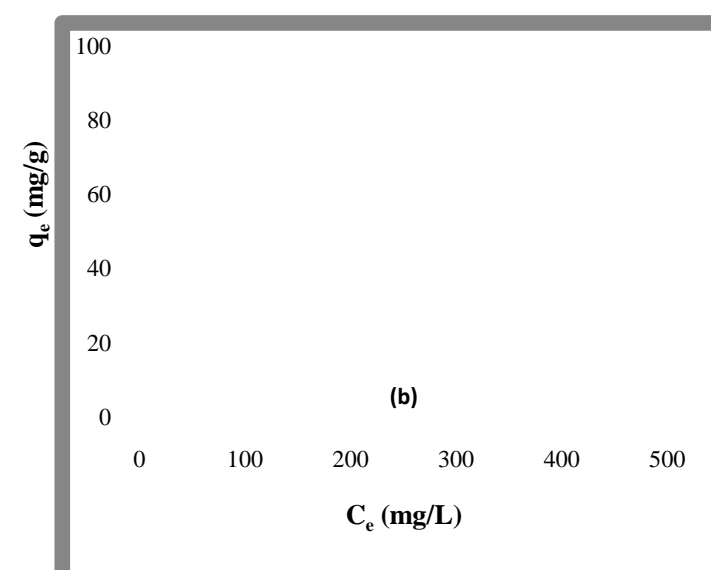

Fig. 4. Effect of initial concentration on adsorption of phosphate onto (a) FeCLW and (b) FeRLW 
The increase in the phosphate ion concentration helps to increases the mass transfer driving force and therefore increases the rate at which phosphate ions pass from the bulk solution to the particle surface that would result in higher adsorption.

\section{Batch isotherm study}

Adsorption of phosphate onto FeCLW and FeRLW gave a linear relationship with Freundlich and Langmuir isotherms which are shown in Figs 5 and 6, respectively. For the adsorption of phosphate, the linear correlation coefficient $\left(\mathrm{R}^{2}\right)$ values for both Freundlich isotherms as shown in Figs 5(a) and 5(b) are found to be slightly higher than that of Langmuir isotherms as shown in Figs 6(a) and 6(b) indicating that the adsorption process was better defined by the Freundlich isotherm model than by the Langmuir isotherm model, which indicated the heterogeneous distribution of active sites on the surface of adsorbents (Lu et al. 2009).
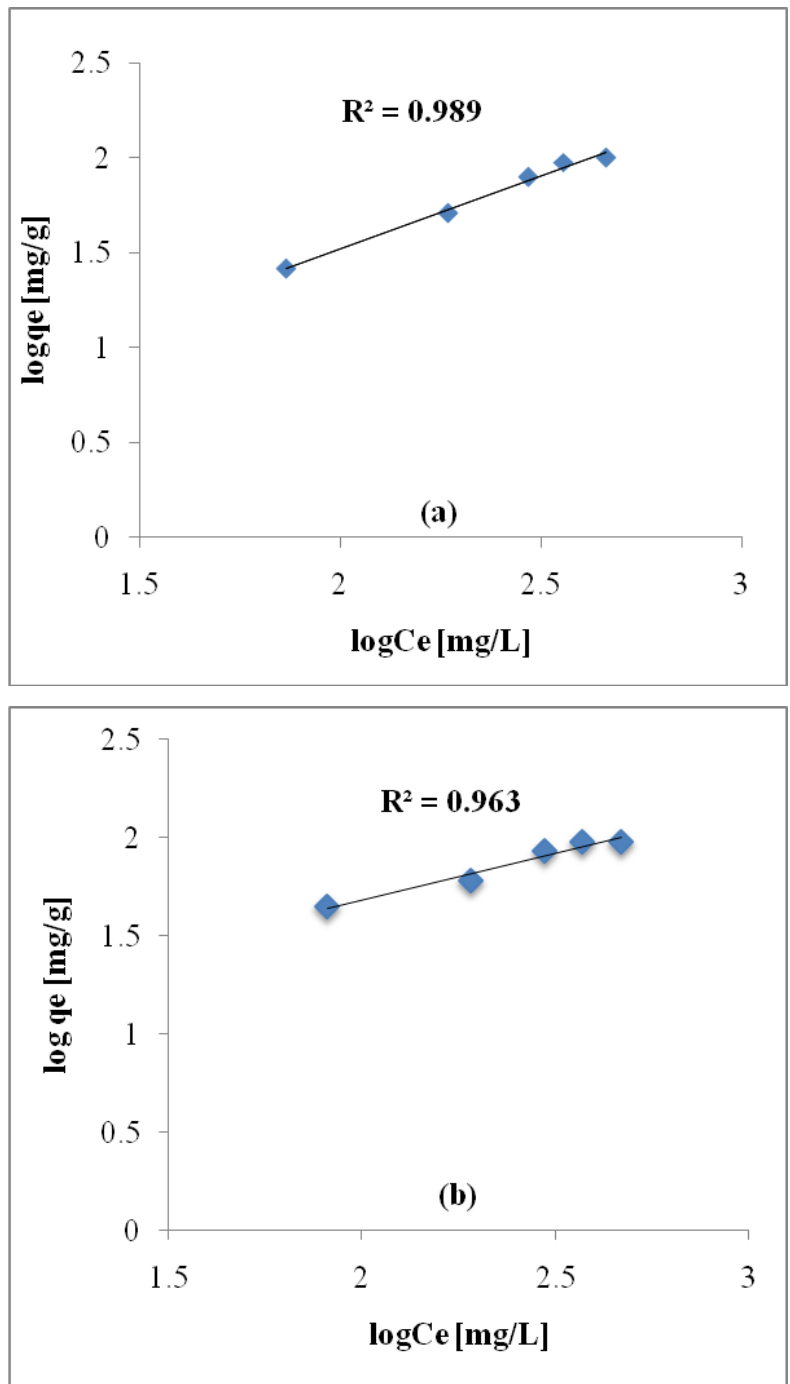

Fig. 5. Freundlich adsorption isotherms for adsorption of phosphate onto (a) FeCLW and (b) FeRLW
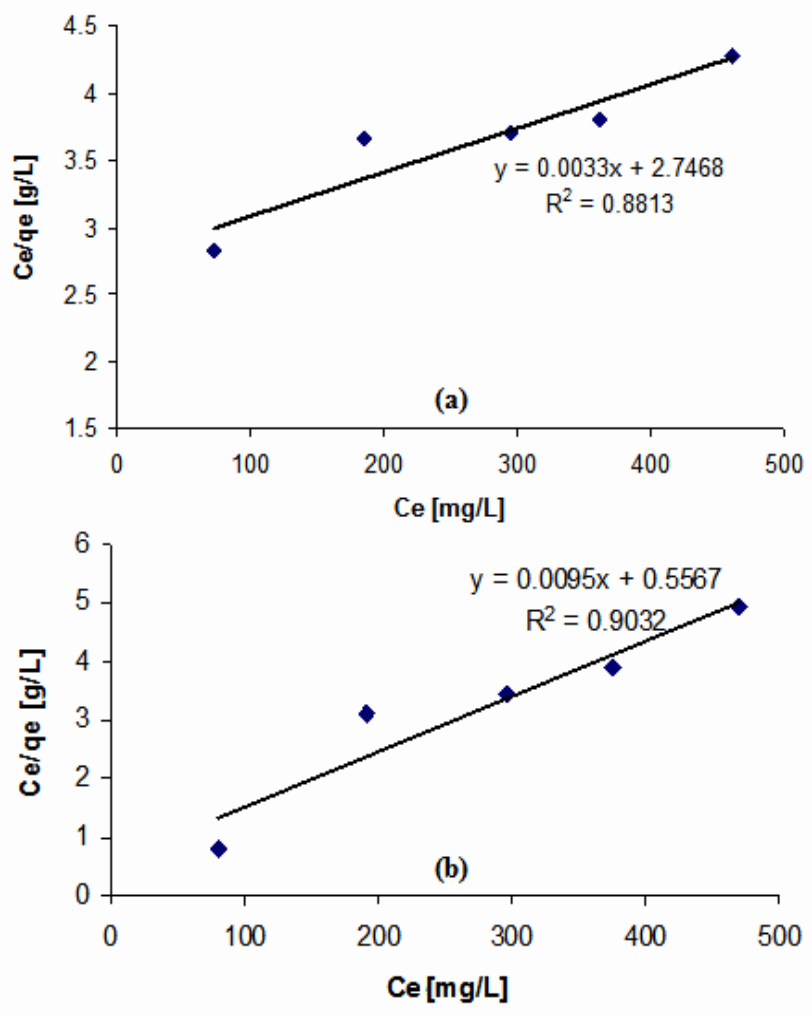

Fig. 6. Langmuir adsorption isotherm for the adsorption of phosphate onto (a) FeCLW and (b) FeRLW

\section{Batch kinetic study}

Kinetic studies for the adsorption of phosphate onto FeCLW and FeRLW were performed using pseudo-first order, pseudo-second order and second order models. The linear correlation coefficient (i.e., $\mathrm{R}^{2}$ ) value for pseudosecond order kinetics was found to be significantly higher than that of pseudo-first order and second order kinetic values (not shown here) among these three tested kinetic models. The $\mathrm{R}^{2}$ value for pseudo-second order kinetic was found to be almost 1 for both bio-adsorbents as shown in Figs 7(a) and 7(b). These results revealed that the best kinetic model for the adsorption of phosphate ion onto FeCLW and FeRLW was found to be pseudo-second order.

\section{CONCLUSION}

The optimum $\mathrm{pH}$ required for the adsorption of phosphate ion onto FeCLW and FeRLW was found to be 3 . The equilibrium contact time for the sorption of phosphate onto both FeCLW and FeRLW were found to be 240 minutes. The optimum dose of both FeCLW and FeRLW for phosphate was $175 \mathrm{mg}$.

The maximum adsorption capacities were found to be 100 $\mathrm{mg} / \mathrm{g}$ for phosphate by FeCLW and $96.5 \mathrm{mg} / \mathrm{g}$ for phosphate by FeRLW, signifying that the bio-adsorbent prepared in this work was effective for the adsorptive removal of phosphate and the results obtained best fitted 
with Freundlich adsorption isotherm, which followed pseudo-second order kinetic model. The maximum adsorption capacities of FeCLW and FeRLW for phosphate adsorption indicated that it can be used as an efficient economical material for the adsorptive removal of phosphate from aqueous system.
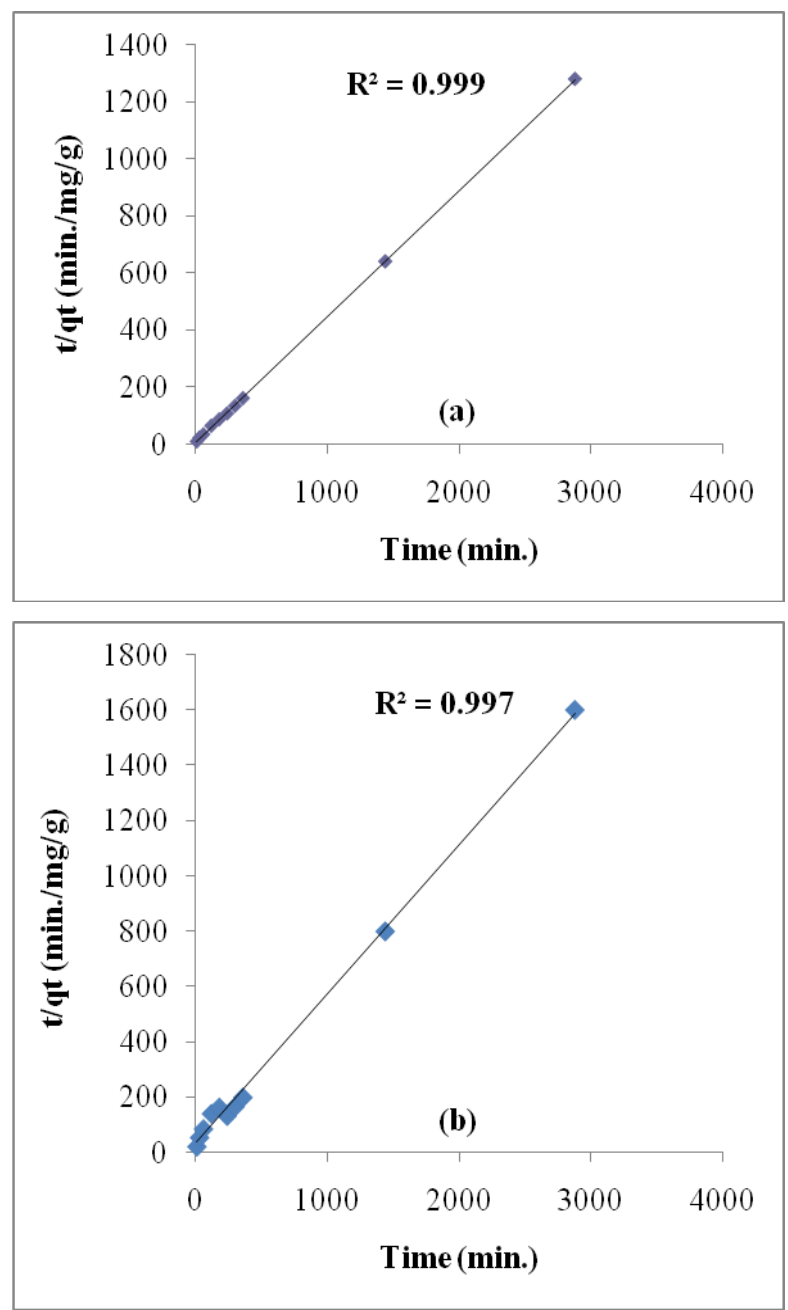

Fig. 7. Pseudo second order kinetic model for adsorption of phosphate onto (a) FeCLW and (b) FeRLW

\section{ACKNOWLEDGEMENT}

The authors are very thankful to the Head of the Department, Central Department of Chemistry, Tribhuvan University, Kirtipur, Kathmandu, Nepal for providing the available research facilities to conduct this research work.

\section{REFERENCES}

Anirudhan, T.S., Noeline, F. and Manohar, D.M. 2006. Phosphate removal from wastewaters using a weak anion exchanger prepared from a lignocellulosic residue. Environmental Science \& Technology 40: 2740-2745.
Batchelor, B. and Dennis R. 1987. Phosphorous removal from effluents in alumina columns. Journal of Water Pollution Control Federation 59(12): 1059-1068.

Bhattarai, P. 2012. Sorption of As(III) and As(V) onto Dalbergia sissoo and Arundo donax sawdust. M. Sc. Dissertation, Central Department of Chemistry, Tribhuvan University, Nepal.

Biswas, B.K., Inoue, K., Ghimire, K.N., Harada, H., Ohto, K. and Kawakita, H. 2008. Removal and recovery of phosphorous from water by means of adsorption on to orange waste gel loaded with zirconium. Bioresource Technology 99: 8685-8690.

Biswas, B.K., Inoue, K., Ghimire, K.N., Ohta, S., Harada, H., Ohto, K. and Kawakita, H. 2007. The adsorption of phosphate from an aquatic environment using metal-loaded orange waste. Journal of Colloid and Interface Science 312: 214-223.

de-Bashan, L.E. and Bashan, Y. 2004. Recent advances in removing phosphorous from waste water and its future use as fertilize. Water Research 38: 42224246.

Inoue, K., Harada, H., Ghimire, K.N., Biswas, B.K., Kawakita, H. and Ohto, K. 2018. Adsorptive removal of phosphorous using metal-loaded biosorbents from aquatic environment. JOJ Material Science 4(2): 555632.

Lu, S.G., Bai, S.Q., Zhu, L. and Shan, H.D. 2009. Removal mechanism of phosphate from aqueous solution by fly ash. Journal of Hazardous Materials 361: 95-101.

Mallampati, R. and Valiyaveettil, S. 2013. Apple peels- a versatile biomass for water purification. ACS Applied Materials \& Interfaces 5: 4443-4449.

Mendham, J., Denney, R.C., Barnes, J.D. and Thomas M.J.K (eds). 2006. Vogel's textbook of quantitative chemical analysis, $6^{\text {th }}$ edition, Pearson Education, pp. 692-694.

Mezenner, N.Y. and Bensmaili, A. 2009. Kinetics and thermodynamic study of phosphate adsorption on iron hydroxide- eggshells waste. Chemical Engineering Journal 147: 87-96.

Nguyen, T.A.H., Ngo, H.H., Guo, W.S., Zhang, J., Liang, S. and Tung, K.L. 2013. Feasibility of iron loaded 'okara' for bio-sorption of phosphorous in aqueous solutions. Bioresource Technology 150: 42-49.

Nguyen, T.A.H., Ngo, H.H., Guo, W.S., Zhang, J., Liang, S., Lee, D.J., Nguyen, P.D. and Bui, X.T. 2014. Modification of agricultural waste/by-products for enhanced phosphate removal and recovery: Potential 
and obstacles. Bioresource Technology 169: 750762.

Pradhan, S. and Pokhrel, M.R. 2013. Spectrophotometric determination of Phosphate in sugarcane juice, fertilizer, detergent and water samples by molybdenum blue method. Scientific World 11(11): 58-62.

Ravindhranath, K., Divya Jyothi, M. and Rohini Kiran, K. 2011. Removal of nitrates from polluted water using bioadsorbents. International Journal of Applied Biology and Pharmaceutical Technology 2(4): 330351.
Shin, E.W., Karthikeyan, K.G. and Tshabalala, M.A. 2005. Orthophosphate sorption onto lanthanum treated lignocellulosic sorbents. Environmental Science \& Technology 39: 379-394.

Tchobanoglous, G. and Burto, F.L. 1991. Wastewater engineering, treatment, disposal and reuse. In: water resources and environmental engineering. Metcalf \& Eddy, McGraw-Hill Series. New York, USA, pp. 733.

Zeng, L., Li, X. and Liu, J. 2004. Adsorptive removal of phosphate from aqueous solution using iron oxide tailings. Water Research 38: 1318-1326. 